\title{
El Estado en un mundo en transformación. Resumen del Informe sobre el desarrollo mundial, publicado por el Banco Mundial en 1997
}

Las miradas del mundo entero están vueltas hacia el Estado. Los trascendentales acontecimientos registrados en la economía mundial nos han obligado a replantearnos algunos interrogantes fundamentales: cuál debe ser el papel del Estado, qué es lo que puede y lo que no puede hacer, cómo debe hacerlo.

Los últimos cincuenta años han demostrado claramente tanto las ventajas como las limitaciones de la acción estatal, en particular en lo que se refiere a la promoción del desarrollo. Los gobiernos han ayudado a introducir sustanciales mejoras en la educación y la salud y a reducir la desigualdad social. Pero la intervención gubernamental también ha tenido consecuencias lamentables. E incluso en los casos en que la actuación anterior del Estado ha sido positiva, muchos temen que no pueda adaptarse a las exigencias de una economía mundial en proceso de globalización.

Son muchas y diversas las nuevas inquietudes e interrogantes sobre la función del Estado; cuatro acontecimientos recientes las han hecho especialmente apremiantes:

- El desplome de las economías dirigidas de la antigua Unión Soviética y de Europa central y oriental (ECO).

- La crisis fiscal del Estado del bienestar en la mayoría de los países con tradición industrial.

- El importante papel desempenado por el Estado en el rmilagro» económico de algunos países del Asia oriental.

- El desmoronamiento del Estado y la multiplicación de las emergencias humanitarias en varias partes del mundo.
En este Informe se hace patente que el factor determinante de esos acontecimientos tan diversos ha sido la eficacia 0 ineficacia de los poderes públicos. Un Estado eficaz es imprescindible para poder contar con los bienes y servicios y las normas e instituciones- que hacen posible que los mercados prosperen y que las personas tengan una vida más saludable y feliz. En su ausencia, no puede alcanzarse un desarrollo sostenible ni en el plano económico ni en el social. Aunque hace cincuenta años muchos hablaban en términos muy semejantes, entonces estas ideas en general involucraban el protagonismo del Estado en el proceso de desarrollo. Lo que la experiencia nos ha enseñado desde entonces es bastante diferente: el Estado es fundamental para el proceso de desarrollo económico y social, pero no en cuanto agente directo del crecimiento sino como socio, elemento catalizador e impulsor de ese proceso.

Los factores que determinan la eficacia del Estado difieren enormemente de un país a otro según las distintas etapas de desarrollo en que se encuentren. Por ejemplo, una misma medida puede dar buenos resultados en los Países Bajos o Nueva Zelandia y resultar contraproducente en Nepal. Incluso cuando el nivel de ingreso es igual, las diferencias de tamaño, configuración étnica, características culturales y sistemas politicos hacen de cada país un ente singular. Pero es precisamente esta diversidad la que amplía la perspectiva de la reflexión de este Informe acerca de por qué y en qué forma algunos Estados consiguen mejor que otros mantener el desarrollo, eliminar la pobreza y adaptarse al cambio. 


\section{Replanteamiento del papel del Estado en todo el mundo}

El mundo está cambiando, y con él cambian también nuestras ideas sobre el papel del Estado en el desarrollo económico y social. La intensa atención que se presta actualmente al papel del Estado nos hace recordar una era anterior, cuando el mundo comenzaba a recuperarse de la destrucción causada por la segunda guerra mundial y gran parte de los paises en desarrollo estaban consiguiendo la independencia. En esa época, el desarrollo parecía un objetivo más asequible, y en gran medida de carácter técnico. Unos asesores y técnicos competentes formularían políticas acertadas, que después serían puestas en práctica por buenos gobiernos en bien de la sociedad. La intervención estatal hacía hincapié en las deficiencias del mercado y asignaba al Estado un papel fundamental en el intento de corregirlas. Pero, desde nuestra perspectiva actual, los supuestos institucionales implícitos en esta cosmovisión eran demasiado simplistas. Parecía que lo más importante era la flexibilidad para aplicar las políticas formuladas por los tecnócratas. La rendición de cuentas a través de sistemas de pesos y contrapesos se veía como un obstáculo.

En algunos países, la situación evolucionó más o menos en la forma prevista por los tecnócratas. Pero, en muchos otros, los resultados fueron muy diferentes. Los gobiernos emprendieron proyectos poco realistas. Los inversionistas privados se abstuvieron por falta de confianza en las políticas públicas o en la firmeza de los dirigentes. Poderosos gobemantes actuaron en forma arbitraria. La corrupción se convirtió en mal endémico. El proceso de desarrollo perdió impulso, y la pobreza se consolidó.

Durante los cien últimos años, la presencia y la intervención del Estado han crecido enormemente, sobre todo en los países industriales (Gráfico 1). Antes de la segunda guerra mundial, la expansión se debió, entre otros factores, a la necesidad de superar los graves daños causados por la Gran Depresión en los sistemas económicos y sociales. La confianza en la intervención estatal durante el período de la posguerra llevó a que se exigiera su intensificación. Las economías industriales ampliaron el Estado del bienestar, y muchos países adoptaron estrategias de desarrollo bajo la dirección estatal. Esto llevó a una enorme expansión de la magnitud y alcance de la función del Estado en todo el mundo. El gasto público representa en estos momentos casi la mitad del ingreso total en los países industriales, y aproximadamente la cuarta parte en los países en desarrollo. Pero ha sido precisamente este incremento de la influencia estatal lo que ha dado lugar a un cambio de orientación: lo que importa ante todo no es lo cuantitativo sino lo cualitativo, no la mera magnitud del Estado y el ámbito de sus intervenciones sino su eficacia para atender las necesidades de la población.

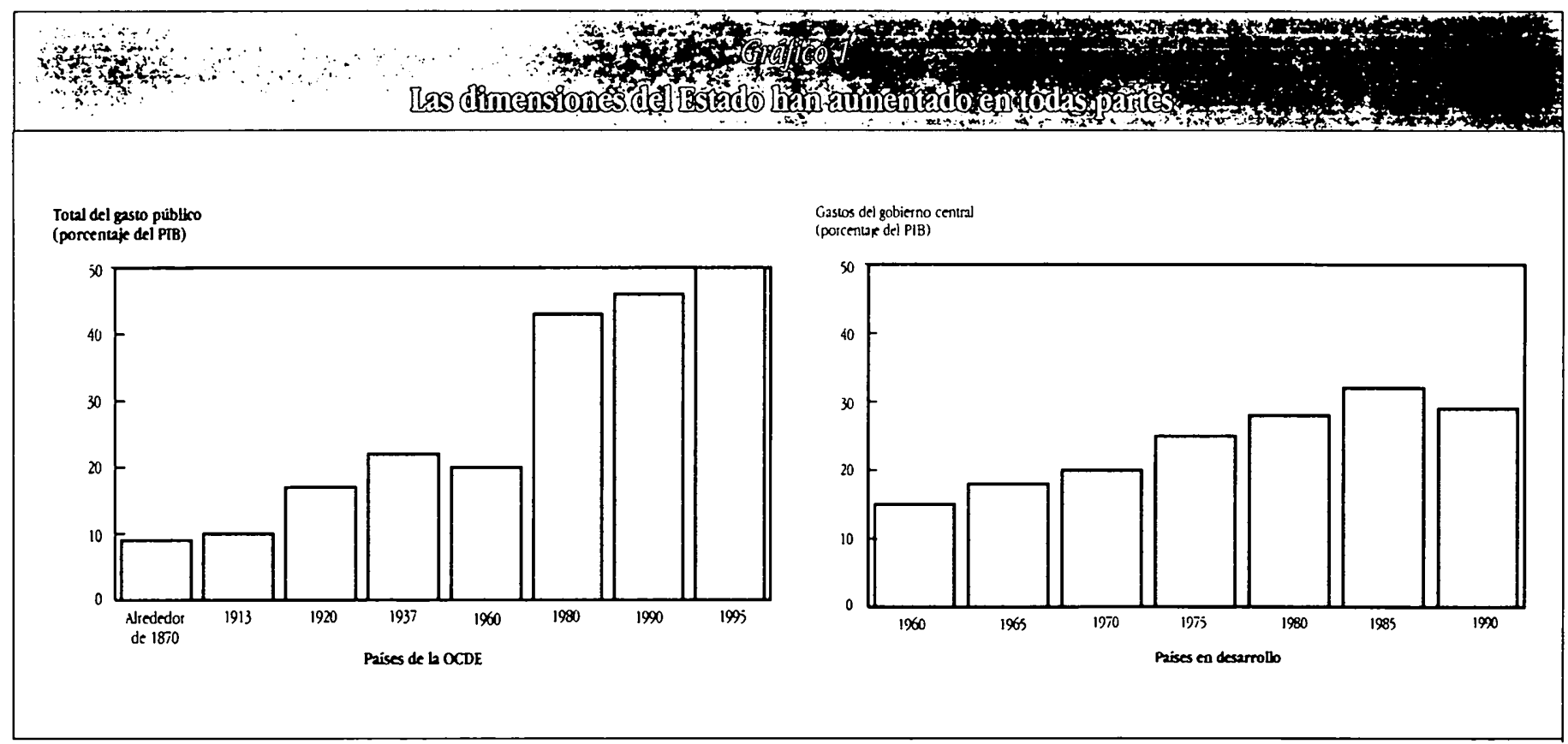

Nota: Los datos sobre los paises de la OCDE corresponden al gobierno central y local, incluidos los gastos de seguridad social. Véase una información más detallada en la Nota técnica. Fuente: TANZ y SCHUNivCHT, 1995; OCDE, varios años; FM1, varios años (b). 
Al igual que en los años cuarenta, el renovado acento en la función y eficacia del Estado ha tenido origen en trascendentales acontecimientos acaecidos en la economía mundial, que produjeron cambios fundamentales en las circunstancias en que se desarrolla la acción estatal. La integración mundial de las economías y la propagación de la democracia han reducido las oportunidades para un comportamiento arbitrario y caprichoso. Los sistemas impositivos, la normativa para la inversión y las políticas económicas deben responder en medida creciente a los parámetros de una economía mundial globalizada. El cambio tecnológico ha abierto nuevas oportunidades para la desagregación de los servicios y la ampliación de las funciones de los mercados. Esos cambios han obligado a los Estados a asumir competencias nuevas y diferentes - no ya como proveedores exclusivos, sino como promotores y reguladores-. El Estado se ve sometido a presiones incluso en aquellos lugares en que su actuación parecía haber sido satisfactoria. Muchos países industriales se debaten con un Estado del bienestar hipertrofiado, y tienen que tomar difíciles decisiones sobre los servicios y prestaciones gubernamentales que los ciudadanos pueden reclamar. Los mercados, tanto nacionales como mundiales, y los ciudadanos, irritados por las deficiencias del sector estatal, exigen, a menudo por intermedio de organizaciones no gubernamentales y de base, una mayor transparencia en las prácticas de gobiemo y otros cambios destinados a fortalecer la capacidad del Estado para alcanzar los objetivos que se le han asignado.

El clamor en favor de una mayor eficacia de los poderes públicos ha alcanzado dimensiones críticas en muchos países en desarrollo en los que el Estado no proporciona ni siquiera bienes públicos fundamentales, como la protección de los derechos de propiedad, la red vial y servicios básicos de salud y educación. El resultado ha sido un círculo vicioso: ante el deterioro de los servicios públicos, los individuos y las empresas evaden el pago de impuestos, lo que a su vez agrava ese deterioro. En la antigua Unión Soviética y en Europa central y oriental fue precisamente la demostrada incapacidad del Estado de cumplir sus promesas lo que en última instancia llevó a su derrocamiento. Pero, a su vez, el desplome de los sistemas de planificación central ha acarreado nuevos problemas. Como consecuencia del vacío creado, los ciudadanos a veces se ven privados de bienes colectivos básicos, como el orden público. En algunos casos extremos, como los de Afganistán, Liberia y Somalia, el Estado se ha desmoronado por completo, y los individuos y los organismos internacionales luchan desesperadamente por resolver esa situación.

\section{Una doble estrategia}

¿Cómo podremos abordar el laberinto de interrogantes y presiones que se ciernen sobre los Estados en todo el mundo?
En este Informe no se propone una panacea universal para conseguir un Estado eficaz. Las diferencias de situación y de puntos de partida son demasiado grandes. Se propone más bien un amplio marco de referencia para abordar el problema de la eficacia del Estado a nivel mundial. Se señalan varias formas de reducir la brecha creciente entre lo que se espera del Estado y su capacidad de respuesta. La solución consistirá, en parte, en lograr que las sociedades acepten una redefinición de las responsabilidades del Estado. Para ello se precisará una selección estratégica de las acciones colectivas que el Estado tratará de promover, junto con mayores esfuerzos para aligerar la carga que pesa sobre el sector estatal mediante la participación de los individuos y las comunidades en el suministro de los bienes colectivos fundamentales.

Pero el proceso de reforma no puede limitarse a reducir o diluir la función del Estado. Incluso con un enfoque más selectivo y una mayor dependencia de la ciudadanía y las empresas privadas, la atención de una amplia gama de necesidades colectivas en forma más satisfactoria exigirá un mejor funcionamiento de las principales instituciones estatales. A fin de elevar el nivel de bienestar de la población, tendrá que ampliarse la capacidad del Estado, es decir, su capacidad de emprender y promover acciones de interés colectivo en forma eficiente.

Este mensaje fundamental se traduce en una doble estrategia para lograr que el Estado participe en forma más creible y eficaz en el proceso de desarrollo de cada país:

- Acomodar la función del Estado a su capacidad. Se trata del primer elemento de la estrategia. Cuando la capacidad del Estado es pequeña, éste debe sopesar cuidadosamente cómo -y dónde- intervenir. Muchos Estados tratan de hacer demasiado con pocos recursos y escasa capacidad, y con frecuencia los perjuicios son mayores que los beneficios. La adopción de un criterio más selectivo centrado en los aspectos fundamentales incrementaría la eficacia de la acción estatal (Recuadro 1). Pero no se trata simplemente de elegir entre lo que se debe y lo que no se deber hacer; hay que decidir también cómo hacerlo.

- Pero la capacidad es una realidad inmutable. Por eso, el segundo elemento de la estrategia consiste en aumentar la capacidad del Estado mediante la revitalización de las instituciones públicas. Ello comprende los siguientes elementos: establecer normas y controles eficaces para poner coto a las medidas estatales arbitrarias y luchar contra la corrupción arraigada; exponer a las instituciones estatales a una competencia mayor a fin de incrementar su eficiencia; mejorar el desempeño de las instituciones estatales mediante el aumento de las remuneraciones e incentivos, y hacer que el sector estatal responda más eficazmente a las necesidades de la 


\section{El camino hacia un Estado más eficaz}

Un Estado más capaz puede ser un Estado más eficaz, pero eficacia y capacidad no son la misma cosa. Capacidad, en el sentido utilizado al referirse al Estado, es la posibilidad de emprender y promover en forma eficiente acciones de interés colectivo, como las relacionadas con el orden público, la salud y la infraestructura básica; la eficacia es resultado de la utilización de esa capacidad para permitir a la sociedad atender su demanda de esos bienes. El Estado puede ser, al mismo tiempo, capaz pero no muy eficaz si su capacidad no se aplica a atender los intereses de la sociedad.

El camino que lleva hacia un Estado más eficaz no es rectilíneo; será, probablemente, un proceso con dos etapas. Primero, el Estado debe concentrar toda su capacidad en las tareas que puede y debe realizar. Conforme vaya avanzando en ello, podrá concentrar sus esfuerzos en conseguir una capacidad adicional. Como puede observarse en el gráfico adjunto, los países de la Zona I, a pesar de su escasa capacidad estatal, realizan una amplia gama de actividades pero en forma dispersa, y sus esfuerzos resultan ineficaces. Sin embargo, los países no pueden pasar a la Zona III de la noche a la mañana, pues la expansión de la capacidad requiere tiempo. Para poder llegar a una mayor eficacia, antes hay que concentrarse en las tareas fundamentales y multiplicar la limitada capacidad del Estado forjando relaciones de asociación con la comunidad empresarial y la sociedad civil (Zona II). Luego, los países podrán avanzar poco a poco hacia la Zona III, ampliando gradualmente su capacidad.

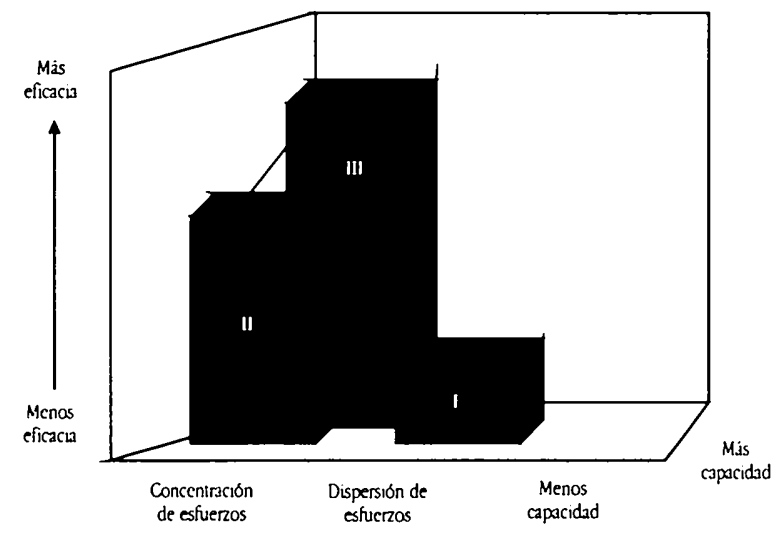

población, cerrando la brecha entre gobierno y pueblo mediante una mayor participación y descentralización. Por ello, en el Informe no sólo se presta atención al replanteamiento de la función del Estado, sino que además se señala la forma en que los países podrían iniciar un proceso de reconstitución de la capacidad estatal.

\section{Acomodar la función a la capacidad}

Cuando se habla de acomodar la función a la capacidad no se quiere decir simplemente que hay que desmantelar el Esta- do. En algunas áreas, lo que se necesita para aumentar la eficacia es un empeño mucho mayor. Por eso, es trascendental distinguir entre lo que se debe y lo que no se debe hacer. Pero para ello hay que decidir también cómo se van a hacer las cosas -cómo prestar los servicios básicos, establecer la infraestructura, regular la economía-, no sólo si se hacen o no. A este respecto, las decisiones pueden y deben ajustarse a las circunstancias de cada país.

\section{Primera función del Estado: asentar bien los cimientos}

La misión del Estado está basada en cinco tareas fundamentales, sin las cuales es imposible alcanzar un desarrollo sostenible y compartido, que resulte en la reducción de la pobreza. Son las siguientes: 
- establecimiento de un ordenamiento jurídico básico;

- mantenimiento de un entorno de políticas no distorsionantes, incluida la estabilidad macroeconómica;

- inversión en servicios sociales básicos e infraestructura;

- protección de los grupos vulnerables, y

- defensa del medio ambiente.

Si bien la importancia de estas tareas esenciales se reconoce ampliamente desde hace largo tiempo, se están perfilando algunos nuevos conceptos acerca de la combinación apropiada de actividades del mercado y del Estado para lograr su consecución. Sobre todo, ahora tenemos conciencia de la complementariedad del Estado y el mercado: aquel es esencial para sentar las bases institucionales que requiere éste. Y la credibilidad de los poderes públicos - la previsibilidad de sus normas y políticas y la coherencia con que se aplican- puede ser tan importante para atraer la inversión privada como el contenido de esas mismas normas y políticas.

Una encuesta entre empresarios del sector formal e informal de 69 países realizada específicamente para este Informe confirma algo que ya se sabía en forma más fragmentaria: que muchas naciones no cuentan con las bases institucionales imprescindibles para el desarrollo del mercado (Recuadro 2). Los elevados niveles de delincuencia y violencia personal y un sistema judicial imprevisible se combinan para constituir lo que en el presente Informe se denomina síndrome de ilegalidad. La debilidad y arbitrariedad de las instituciones estatales agravan muchas veces la situación con su comportamiento imprevisible y contradictorio. De esa manera, lejos de contribuir al crecimiento del mercado, lo perjudican, y socavan la credibilidad del Estado.

A fin de alcanzar un desarrollo estable y sostenible, el Estado tiene que centrar su atención en los factores sociales fundamentales. La ilegalidad a menudo tiene su origen en la marginación: en realidad, los desheredados pueden llegar a convencerse de que la vulneración de la ley es la única forma de hacerse escuchar. Las políticas públicas pueden asegurar que el crecimiento sea compartido por todos y contribuya a reducir la pobreza y la desigualdad, pero sólo si los gobiemos atribuyen una elevada prioridad a los factores sociales fundamentales.

Con demasiada frecuencia las políticas y programas impiden que los recursos y servicios lleguen a las personas que más los necesitan. A causa de la influencia política de los segmentos más pudientes de la sociedad, algunas veces los gobiemos gastan mucho más en educación universitaria para los estudiantes ricos y de clase media que en educación básica para la mayoría de la población y en becas para los más necesitados. En muchas regiones, la pobreza y la desigualdad con frecuencia afectan en forma desproporcionada a las minorías étnicas y a las mujeres, o a las zonas geográficas desfavorecidas. Como resulta cada vez más evidente en muchas partes del mundo, estos grupos, marginados del debate público y excluidos del conjunto de la economía y la sociedad, constinuen tierra fértil para la violencia y la inestabilidad.

Las políticas y programas públicos deben orientarse no sólo a fomentar el crecimiento estimulado por el mercado, sino también a asegurar la distribución de sus beneficios, particularmente mediante inversiones en servicios básicos de educación y salud. Además, deben proteger a la población contra la inseguridad material y personal. Cuando la pobreza y la marginación económica tienen su origen en diferencias étnicas y sociales, las políticas deben articularse cuidadosamente en función de estas diferencias, como se ha hecho en Malasia y Mauricio.

La regulación gubernamental no es la única respuesta a la contaminación. Hoy existe la posibilidad de utilizar una serie de incentivos innovadores y flexibles para conseguir que quienes contaminen reparen los daños causados. Aunque no hay nada que pueda sustituir a unos marcos normativos acertados ni a la información sobre el medio ambiente, esos nuevos instrumentos, basados en la persuasión, la presión social y la capacidad del mercado para inducir comportamientos más ecológicos, pueden muchas veces dar fruto donde los reglamentos no lo consiguen. Los países están utilizando algunas de esas herramientas, con resultados alentadores, en la búsqueda de cuatro objetivos:

- encauzar la fuerza de la opinión pública;

- conseguir una reglamentación más flexible;

- aplicar mecanismos autorreguladores, y

- elegir instrumentos eficaces y basados en el mercado.

\section{Construir sobre los cimientos: el Estado no tiene la exchusiva}

Es un hecho cada vez más aceptado que, en muchos países, los monopolios públicos de infraestructura, servicios sociales y otros bienes y servicios tienen pocas probabilidades de ser eficaces. Al mismo tiempo, las nuevas tecnologías y sistemas de organización han creado nuevas oportunidades para que proveedores privados competitivos participen en actividades hasta ahora reservadas al sector público. Para aprovechar estas nuevas oportunidades y lograr una asignación más eficiente de la escasa capacidad pública, los gobiernos están empezando a hacer una distinción entre el financiamiento de las obras de infraestructura y los servicios, por un lado, y su suministro, por el otro, y entre los segmentos competitivos del mercado de servicios públicos y los segmentos monopolísticos. Los países partidarios de la reforma también están tomando medidas para distinguir entre los programas de seguro social, encaminados a 
Recuadro 2

Credibilidad, inversión y crecimiento

Una encuesta entre empresarios locales de 69 países ha revelado que la forma en que muchos Estados realizan sus funciones fundamentales deja mucho que desear; no logran asegurar el orden público, proteger la propiedad ni aplicar las normas y políticas en forma previsible. Los inversionistas desconfian de esos Estados, lo que, a su vez, representa un obstáculo para el crecimiento y la inversión.

En la encuesta citada se pidió a las empresas que clasificaran cada indicador en una escala que iba del uno (problema extremo) al seis (ningún problema). El promedio de las respuestas, como puede verse en el panel de la izquierda en relación con las distintas regiones del mundo, arroja un indicador global de la fiabilidad del marco institucional (normalizado aquí con los países de alto ingreso de la OCDE) tal como la perciben los empresarios privados; es lo que denominamos índice de credibilidad. En los otros dos paneles se observa que, una vez controladas las diferencias de nivel de ingreso y educación y las distorsiones de las políticas, existe una fuerte correlación entre el índice de credibilidad asignado a los países y su historial en materia de crecimiento e inversión. Las calificaciones sobre la credibilidad están basadas en impresiones de los inversionistas, pero son esas impresiones las que determinan su forma de invertir.
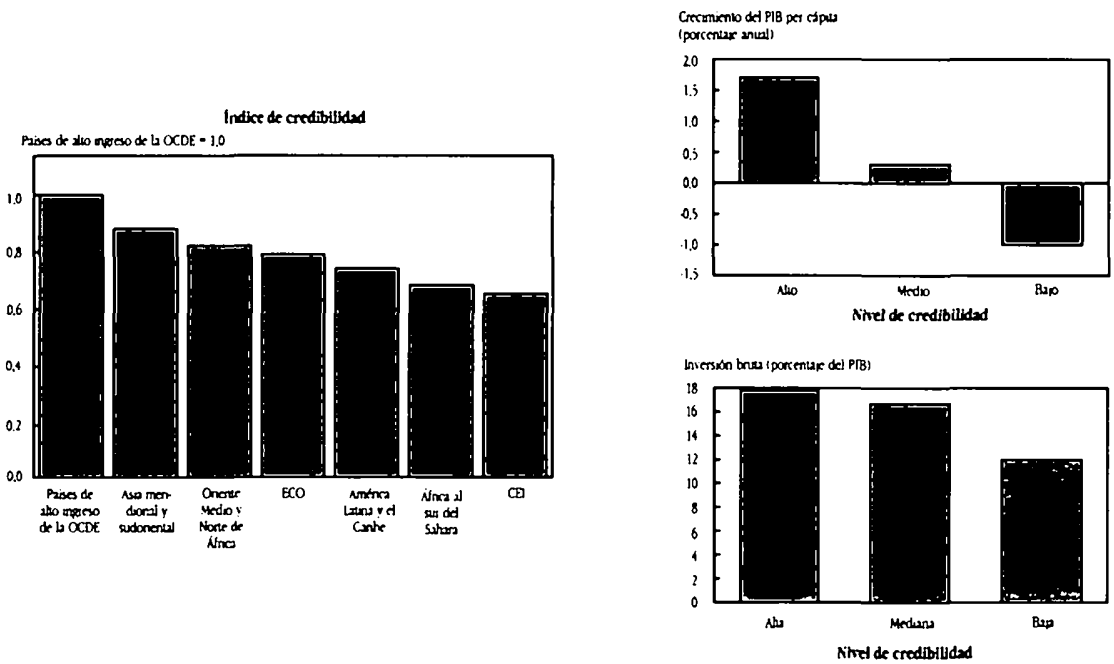

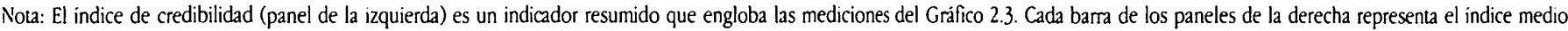

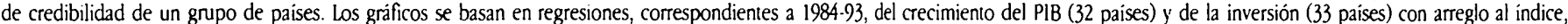

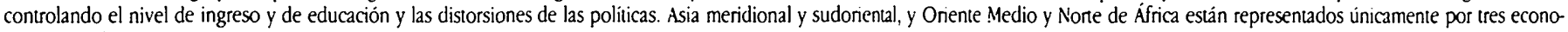
mias, en cada caso.

Fuente. Cálculos del personal del Banco Mundial basados en datos da la encuesta del sector privado realizada para este Informe y en los documentos de antecedentes de Brunetri, Kislikko y Weder.

atender la salud y los problemas de inseguridad en el empleo de toda la población, y los de asistencia social, destinados a ayudar únicamente a los grupos más pobres de la sociedad.

\section{Acabar con la inseguridad económica en el hogar}

Es un hecho comprobado que el Estado puede ayudar a los hogares a eliminar ciertos factores que plantean riesgos para su seguridad económica: puede evitar la miseria en la vejez a través de sistemas de pensiones, puede ayudar a hacer frente a enfermedades catastróficas mediante seguros de salud y puede brindar asistencia en caso de la pérdida del trabajo con seguros de desempleo. Pero la idea de que esta carga debe recaer únicamente sobre el Estado ha comenzado a cambiar. El Estado del bienestar se está reformando incluso en muchas naciones industriales. Las economías emergentes, desde Brasil hasta China, no podrán sufragar el costo de planes inspirados en el sistema europeo, ni siquiera de versiones limitadas de los mismos, especialmente si se tiene en cuenta el rápido envejecimiento de su población. Para lograr una mayor seguridad a un costo menor, se necesitan soluciones innovadoras basadas en la partici- 
pación de las empresas, los trabajadores, los hogares y los grupos comunitarios. Esto es particularmente importante para los países en desarrollo que todavía no se han comprometido con planes de alto costo.

\section{Reglamentación eficaz}

Una normativa debidamente formulada puede ayudar a la sociedad a aprovechar las fuerzas del mercado en beneficio de los fines públicos. La reglamentación puede contribuir a proteger a los consumidores, a los trabajadores y al medio ambiente. Puede estimular la competencia y la innovación y, al mismo tiempo, poner coto a los abusos de los poderes monopolísticos. Gracias a las reformas normativas emprendidas a principios del decenio de 1980, el sector de las telecomunicaciones de Chile ha alcanzado niveles sostenidos de inversión privada, servicios de mejor calidad, una mayor competencia y precios más bajos. En cambio, en Filipinas, hasta la implantación de las reformas recientes, una reglamentación disfuncional privaba de inversiones al sector de las telecomunicaciones, desde hacía tiempo en manos del sector privado. Por esta razón, el servicio era deficiente y las tarifas elevadas, en muchos casos, lo que suponía altos costos para la población y el sector empresarial. Las nuevas posibilidades de prestación de servicios sociales y de infraestructura por parte del sector privado sólo se harán realidad, en muchas ocasiones, si existe un marco normativo satisfactorio.

\section{Politica industrial}

Cuando los mercados están subdesarrollados, el Estado puede a veces aliviar los problemas de coordinación y las deficiencias de información y promover el desarrollo del mercado. Muchas de las economias con mayor tradición industrial se valieron de diversos mecanismos para estimular el crecimiento del mercado en sus etapas iniciales de desarrollo. Más recientemente, el Japón, la República de Corea y otros países de Asia oriental, además de asegurar la existencia de los factores económicos, sociales e institucionales fundamentales, han utilizado toda una gama de instrumentos para la promoción del mercado. En algunos casos, las intervenciones han sido bastante complejas, por ejemplo, el uso de subvenciones en forma muy estratégica. Otras intervenciones, como la promoción de las exportaciones y los incentivos especiales a la infraestructura, han sido de alcance más limitado. La sabiduría en la elección de las intervenciones más apropiadas y la eficacia en su aplicación revisten importancia crítica; la adopción de políticas inadecuadas en las áreas del comercio, el crédito y la industria puede tener $-\mathrm{y}$ de hecho ha tenido- consecuencias muy perjudiciales. Muchos países en desarrollo adoptaron políticas industriales agresivas desafortunadas, con resultados desastrosos. Las naciones que han aplica- do con éxito una política industrial dinámica son las que contaban con una sólida capacidad instiucional.

\section{Gestión de la privatización}

Una normativa cuidadosamente estructurada y otras iniciativas gubernamentales pueden impulsar el crecimiento del mercado. Pero en muchos países este proceso puede ser muy lento, pues la iniciativa privada está a merced de las relaciones de enfrentamiento entre Estado y mercado, heredadas del pasado. Además, las empresas estatales improductivas a menudo constituyen una pesada carga para las finanzas estatales. Una solución obvia es la privatización. Lo que ocurre es que, en general, es más fácil vender los activos del Estado cuando se dan condiciones propicias para el desarrollo del sector privado. Por eso, en casos como los de China, Corea y Taiwán (China) se ha optado por no dar máxima prioridad a la privatización y permitir que el sector privado crezca en torno al sector estatal. № obstante, es posible que no se pueda seguir ese camino en los lugares donde la presión fiscal es muy fuerte y donde la presencia de empresas estatales ineficientes impide la necesaria reestructuración general de la economía.

La experiencia ha demostrado que la forma en que se lleva a cabo la privatización influye de forma trascendental en los resultados finales. Los factores clave son la transparencia del proceso, la aceptación por parte de los empleados, la generación de una amplia base de propiedad y la implantación de reformas normativas apropiadas. En los casos en que la privatización se ha aplicado con cautela, son ya visibles los resultados positivos, por ejemplo, en Chile y la República Checa. Si bien su importancia en la estrategia para la promoción del mercado puede variar de un caso a otro, muchos países en desarrollo que desean reducir la magnitud de su desmesurado sector estatal deben conceder máxima prioridad a la privatización. Un proceso de privatización bien administrado produce grandes beneficios económicos y fiscales.

\section{Determinación de los límites de la acción estatal}

La clave para la aplicación de las políticas en forma previsible y coherente es la armonía entre la capacidad de las instituciones estatales y su actuación. Los Estados con un nivel suficiente de desarrollo suelen tener una considerable capacidad administrativa, y sus sistemas institucionalizados de pesos y contrapesos impiden la adopción de medidas arbitrarias al mismo tiempo que brindan a las organizaciones estatales la flexibilidad necesaria para realizar su cometido. En cambio, los Estados con instituciones más débiles quizás prefieran pecar de falta de flexibilidad y exceso de control. Pueden hacerlo en dos maneras: 
- Mediante la aplicación de normas autorrestrictivas que especifiquen con precisión el ámbito de las políicas y las incorporen en mecanismos cuya derogación sea costosa. Ejemplos de estos mecanismos en la esfera de la políica monetaria son los acuerdos regionales que entrañan el uso de una moneda común, como el existente entre los países francoparlantes de África, o las juntas cuasimonetarias, como la de la Argentina. Los contratos firmes de compra (sin derecho de rescisión) con productores independientes de energía eléctrica cumplen una función semejante en la reglamentación de los servicios públicos.

- Mediante acuerdos de asociación con empresas e individuos. Por ejemplo, en el campo de la política industrial, los Estados pueden fomentar la colaboración dentro del propio sector privado; en el de la reglamentación financiera, pueden ofrecer a la banca incentivos para que actúe con prudencia, $y$, en lo que se refiere a la protección del medio ambiente, pueden difundir información para estimular la presentación de iniciativas ciudadanas «de abajo arriba*.

Los países en transición deben hacer frente a un desafío especial: no están cambiando sólo las funciones, como consecuencia de la adopción de sistemas basados en el mercado; también se están transformando las capacidades. Algunos países en transición conservan capacidades en forma de personal calificado y equipo utilizable, pero no están debidamente organizados para el desempeño de sus nuevas funciones. En ocasiones se encuentran ejemplos aislados de calidad en medio de un mar de mediocridad. En esos casos, la búsqueda de una mayor eficacia resulta al mismo tiempo más fácil y más difícil: más fácil, porque el punto de partida de la capacidad no es demasiado bajo; más difícil, porque para reconstruir la capacidad hay que cambiar las actitudes. La reforma no consiste simplemente en asignar a las personas nuevas responsabilidades.

\section{Revitalización de las instituciones estatales}

Reconocer la capacidad real del Estado, quizá muy escasa, no significa aceptarla para siempre. La segunda tarea clave de la reforma del sector estatal consiste en revitalizar su capacidad institucional ofreciendo a los funcionarios públicos incentivos para mejorar su rendimiento $y$, al mismo tiempo, manteniendo a raya las posibles arbitrariedades.

A los países les resulta difícil establecer las instituciones necesarias para asegurar la eficiencia de su sector público. Una de las razones de esa dificultad es de orden político. Por ejemplo, es posible que haya fuertes intereses empenados en mantener un statu quo injusto e ineficiente, mientras que los perjudicados por esa situación quizás no estén en condiciones de ejercer presiones eficaces para cambiarla.

Ahora bien, el problema de la ineficiencia o corrupción crónicas no es exclusivamente de carácter político. Con frecuencia, los políticos y otros cargos públicos tienen fuertes incentivos y un sincero deseo de mejorar el sector público. Pero la gestión de una burocracia es una tarea compleja, para la que no se pueden ofrecer soluciones claras e inequivocas. En realidad, para establecer instituciones que aseguren la eficacia del sector público es preciso resolver toda una serie de problemas básicos de comportamiento que distorsionan los incentivos y, en última instancia, llevan a resultados insatisfactorios. Según las circunstancias, son tres los tipos básicos de incentivos que se pueden utilizar para luchar contra estos problemas más profundos y mejorar la capacidad (Gráfico 2). Son los siguientes:

- normas y controles eficaces;

- más competencia, y

- consulta y participación ciudadana.

\section{Normas y controles eficaces}

A largo plazo, para crear un clima general de responsabilidad se necesitan mecanismos formales de control, anclados en las instituciones estatales básicas. El poder puede dividirse ya sea entre los órganos judiciales, legislativos y ejecutivos del Estado, o entre las autoridades centrales, provinciales y locales. Cuanto más amplia es la separación de poderes, mayor es el número de instancias de control que pueden evitar las medidas estatales arbitrarias. Pero la existencia de múltiples instancias de control es una espada de doble filo, pues puede hacer que resulte tan difícil modificar las normas periudiciales como las beneficiosas.

En muchos países en desarrollo la supervisión legislativa y judicial del poder ejecutivo es débil. La fijación de metas y la vinculación de éstas con las políticas necesarias para su consecución son a veces poco claras, las legislaturas adolecen de falta de información y capacidad, y la independencia de la judicatura está en entredicho. Un poder judicial independiente es vital para asegurar que los poderes legislativo y ejecutivo asuman su plena responsabilidad ante la ley, y para interpretar y hacer cumplir las disposiciones de la Constitución nacional. Es fácil redactar leyes; luego, hay que hacerlas cumplir para que el país pueda disfrutar de los beneficios privativos del Estado de Derecho. Se requiere mucho tiempo para establecer estas instituciones de control, pero a corto plazo se pueden sustituir con mecanismos de compromiso supranacionales, como los sistemas de adjudicación o las garantías de los organismos internacionales. 


\section{Giverictico 2}

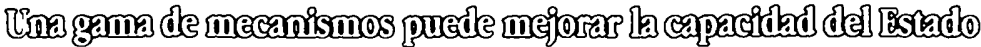

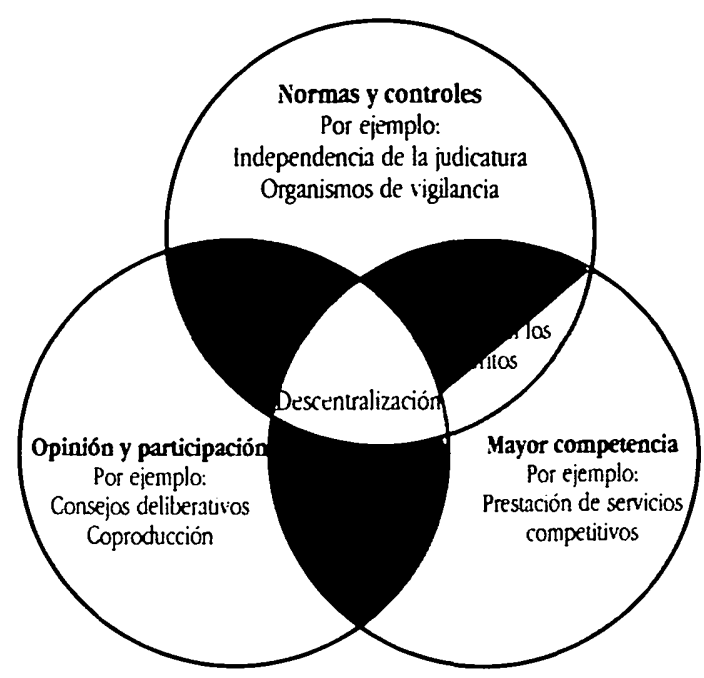

Toda estrategia eficaz encaminada a revitalizar el sector público deberá hacer especial hincapié en aminorar las oportunidades de corrupción recortando las facultades discrecionales. Todas las medidas de política orientadas a reducir los controles al comercio exterior, eliminar las barreras que obstaculizan el acceso de la industria privada y privatizar empresas estatales en una forma que asegure la competencia son beneficiosas en la lucha contra la corrupción (Gráfico 3). En este terreno hay que actuar con decisión: las reformas que abren oportunidades para la participación de la empresa privada en sectores de la economía que le estaban vedados, pero que dejan ese acceso a la discrecionalidad de los funcionarios públicos en vez de establecer procesos abiertos y competitivos, crean también enormes posibilidades de corrupción. Un sistema formal de pesos y contrapesos puede coadyuvar asimismo a reducir la corrupción existente en los medios oficiales, pero, por sí solo, casi nunca resulta suficiente. Las reformas de la administración pública, la adopción de medidas para reducir el clientelismo político y una mejor remuneración de la administración pública han ayudado también a reducir la corrupción, ya que han incentivado a los funcionarios públicos a actuar de acuerdo con las normas establecidas.

En los casos en que la corrupción está muy arraigada, será necesario desplegar esfuerzos mucho más intensos para eliminar esa lacra. Estos esfuerzos deben centrarse en el seguimiento más eficaz de la actuación de los medios oficiales - tanto por instituciones reconocidas como por individuos- y en la sanción de las infracciones por los tribunales. La comisión independiente contra la corrupción que funciona en Hong Kong (China, a par- tir del 1 de julio de 1997) es un ejemplo elocuente de lo que se puede conseguir con este enfoque. Asimismo, las reformas implantadas recientemente en Uganda han incorporado varios de los elementos de la estrategia de lucha contra la comupción aquí esbozada, y se han obtenido resultados alentadores. Estos mismos mecanismos podrían aplicarse en todo el mundo: pese a todas las afirmaciones en sentido contrario, la corrupción no es un problema vinculado a una cultura específica. Para combatirla habrá que luchar en varios frentes y recabar una mayor participación del sector privado y la sociedad civil. El que soborna es tan responsable como el sobornado y, por lo tanto, la imposición de fuertes sanciones a las empresas nacionales e internacionales debe formar parte de la solución.

\section{Alentar la competencia}

Los gobiernos pueden incrementar su capacidad y eficacia alentando una competencia mucho mayor en diversas esferas: en los procesos de contratación y de ascensos, en la formulación de las políticas y en la forma en que prestan sus servicios.

\section{Mayor competencia dentro de la Administración Pública}

Un factor fundamental para la eficacia del Estado es la existencia de un cuerpo de funcionarios capaz y motivado, tanto si se dedican a la formulación de políticas como a la prestación de servicios o a la administración de contratos. Para motivarlos a actuar en 


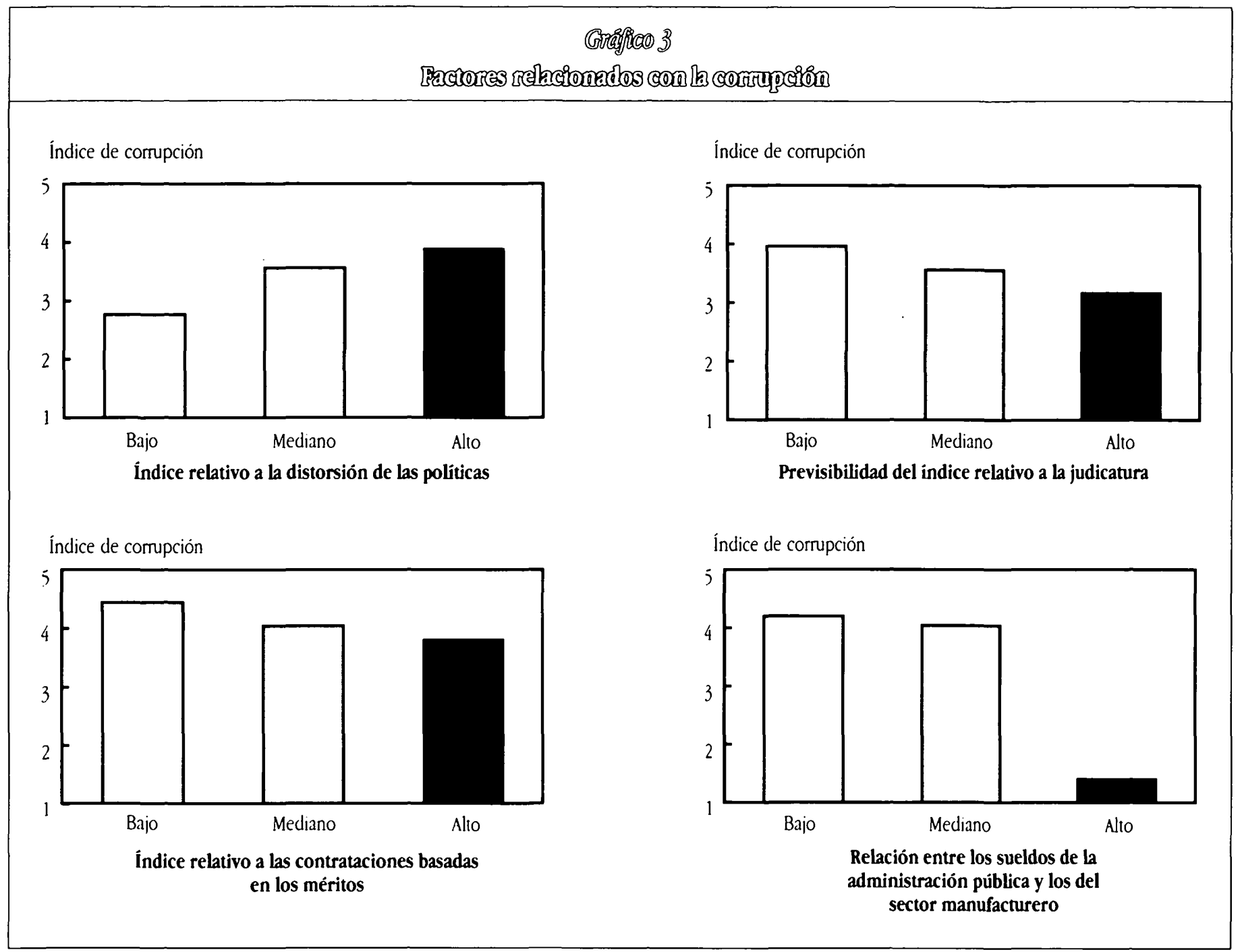

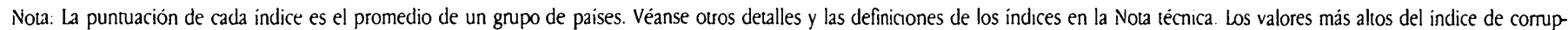

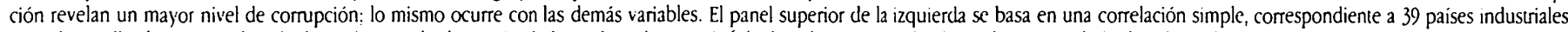

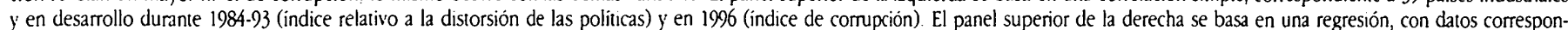

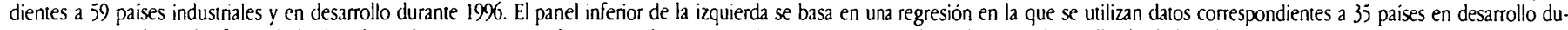

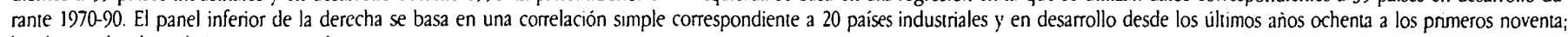
los datos sobre los salarios son promedios.

Fuente: Cálculos del personal del Banco Mundial.

forma eficiente se pueden combinar los siguientes mecanismos orientados a estimular la competencia interna:

- un sistema de contratación basado en los méritos, no en el favoritismo;

- un sistema de ascensos internos también fundamentado en los méritos, y

- una remuneración suficiente.

En el siglo XIX todas las naciones que cuentan hoy con una firme tradición industrial comenzaron a establecer modernas burocracias profesionales asentadas en estos principios. Más recientemente, los han adoptado también muchos países de Asia oriental, que han transformado unas burocracias débiles, comuptas y basadas en el clientelismo político en sistemas que funcionan razonablemente bien. Pero muchos países en desarrollo no necesitan buscar modelos en otras naciones ni remontarse a la historia: pueden encontrarlos en sus propias instituciones. Por ejemplo, los bancos centrales a menudo funcionan eficazmente y siguen siendo competentes aun en los casos en que se han deteriorado todas las demás instituciones. Estos organismos funcionan satisfactoriamente por las razones antes mencionadas. Están menos sujetos a injerencia política. Tienen objetivos limitados pero claros. Reciben recursos y capacitación suficientes. Y su personal suele estar mejor remunerado que el de otras dependencias gubernamentales. 
La comparación entre los datos de distintos países revela que las burocracias más capaces son las que cuentan con sistemas de contratación y promoción más competitivos y basados en los méritos y niveles más elevados de remuneración. En varios países (Filipinas y Kenya, por ejemplo) está muy arraigada la práctica de efectuar los nombramientos teniendo en cuenta consideraciones políticas, mientras que otros, como Corea, se han beneficiado con la utilización de planes de contratación y ascensos muy competitivos que recompensan explícitamente los méritos. En el actual proceso de reforma de Filipinas se están examinando estos problemas con el fin de mejorar la capacidad de la administración pública. En general, los países con sistemas débiles de pesos y contrapesos tienen que hacer más hincapié en la transparencia y la competitividad. La experiencia de algunas economías de Asia oriental con un gran crecimiento económico también demuestra que la meritocracia y la recompensa a largo plazo de los méritos profesionales ayudan a crear un sentimiento de solidaridad o compromiso común con las metas colectivas. Esto reduce los costos de transacción contraídos para hacer observar las limitaciones internas y contribuye a forjar nexos internos y un espíritu de lealtad.

Los sueldos de los funcionarios públicos se han deteriorado en muchos países en desarrollo a causa de la expansión del empleo en los niveles más bajos de formación y de las limitaciones fiscales que afectan al total de los costos salariales (Gráfico 4). El resultado ha sido una considerable compresión de las estructuras salariales y unos niveles de remuneración muy poco competitivos para los funcionarios superiores, factores que dificultan la contratación y retención de personal competente. Algunos países, como Uganda, han emprendido reformas de gran alcance para recortar sustancialmente el exceso de personal, elevar la remuneración media y ampliar la estructura salarial. Pero muchos países todavía no han empezado a abordar estos problemas.

\section{Mayor competencia en la provisión de bienes y servicios püblicos}

En muchos países en desarrollo los sistemas de prestación de servicios son deficientes o inexistentes. Los políticos intervienen a menudo en las actividades cotidianas de los organismos públicos y el personal directivo tiene escasa flexibilidad. La obligación de rendir cuentas de los resultados es limitada. Además, en muchos de estos países el sector público goza de monopolio, lo que limita las presiones en favor de una mayor eficiencid.

Para el establecimiento de un sector público eficaz en estas circunstancias se requiere la apertura de las principales instiruciones gubernamentales, a fin de mejorar los incentivos en esferas que durante mucho tiempo han estado monopolizadas por el sector estatal. Decenas de países de las Américas, Europa y

\section{Gráfico 4}

Cuanto más numerosos son los funcionarios públicos más bajos suelen ser sus salarios

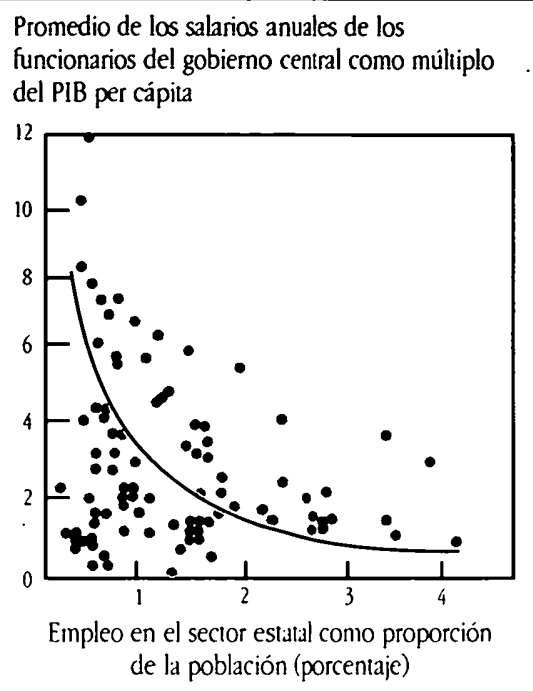

Nota: Los datos corresponden a 96 paises industriales y en desarrollo durante varios anos a principios del decenio de 1990 . Véase la Nota técnica.

Fuente: Documento de antecedentes de Schiavo-Campo, de Tommaso y Mukherjee.

Asia, aprovechando los cambios tecnológicos, han introducido la competencia en las telecomunicaciones y la generación de energía eléctrica. El resultado ha sido la reducción de los costos unitarios y la rápida expansión de los servicios. Otro dispositivo utilizado para estimular la competencia es la licitación y subasta de los servicios públicos. Esta tendencia es significativa en las naciones industriales (Reino Unido, Estado de Victoria en Australia), pero también los países en desarrollo están empleando mecanismos de esta índole para mejorar la eficiencia (mantenimiento de la red vial en el Brasil, por ejemplo). Debido a su escasa capacidad administrativa, algunos países (Bolivia, Uganda) prestan los servicios sociales mediante contratos con organizaciones no gubernamentales.

Existe una tendencia creciente a establecer organismos públicos orientados a fines concretos y fundamentados en criterios específicos de desempeño, con objetivos más claros y mayor responsabilidad administrativa respecto de los productos o resultados. Entre las naciones de alto ingreso el ejemplo más impresionante en este sentido es Nueva Zelandia, que ha desarticulado sus grandes ministerios con funciones múltiples y creado numerosas unidades orientadas a objetivos específicos, cuyos directivos tienen contratos a plazo fijo y basados en los resultados pero gozan de autoridad para contratar y despedir al personal así como para realizar negociaciones colectivas. Singapur aplica descle hace tiempo un enfoque semejante, plasmado en las jun- 
tas oficiales basadas en criterios específicos de desempeño. Otros países en desarrollo han adoptado medidas similares; Jamaica, por ejemplo, está estableciendo organismos ejecutivos inspirados en el modelo británico.

Ahora bien, los países con controles inadecuados e insuficiente capacidad deben proceder con cautela. En esas condiciones, al otorgar mayor flexibilidad a los gerentes del sector público lo que se consigue es aumentar la arbitrariedad y la corrupción, sin mejorar los resultados. Debe tenerse presente también que para poder redactar y exigir el cumplimiento de contratos que entrañan la obtención de complejos resultados se requiere personal especializado, que escasea en muchos países en desarrollo. Estos países necesitan ante todo mejorar el cumplimiento de la normativa vigente e imponer una mayor responsabilidad financiera en su sector público (como han hecho Argentina y Bolivia), formular con mayor claridad los objetivos y tareas, e implantar sistemas de medición del desempeño (como en los casos de Colombia, México y Uganda). A medida que se fortalezcan los sistemas de medición de los resultados y los controles ex post de los insumos, podrá darse mayor flexibilidad a los organismos a cambio de que asuman más responsabilidad por los resultados.

\section{Acercamiento del Estado a la sociedad}

La eficacia del Estado es mayor cuando se escuchan las opiniones del sector empresarial y de la ciudadanía en general y se propicia la participación de ambos grupos en la determinación y aplicación de las políticas. Cuando los gobiernos carecen de mecanismos para escuchar estas opiniones, no responden a los intereses de la población, en particular de los grupos minoritarios y los pobres, a los que suele resultarles muy dificil hacer oír su voz en las altas esferas del poder. Es probable que ni siquiera los gobiemos mejor intencionados puedan satisfacer las necesidades colectivas en forma eficiente si no saben cuáles son esas necesidades.

\section{Escuchar a los ciudadanos}

Para que haya participación, hay que hacer llegar el sentir de los grupos pobres y marginados al centro mismo del proceso de formulación de políicas. En muchos países, la capacidad de los grupos para hacerse escuchar está tan mal repartida como los ingresos. La disponibilidad de más información y una mayor transparencia son elementos vitales para entablar un debate público bien orientado y para incrementar la confianza del pueblo en el Estado, tanto cuando se examinan las prioridades de gasto como cuando se formulan los programas de asistencia social o se ordenan los recursos forestales y de otro tipo. Las encuestas de clientes (en la India, Nicaragua y Tanzanía) y las cartas de derechos ciudadanos (en Malasia) constituyen nuevos medios para hacer escuchar la voz de estos grupos.

Las urnas electorales son el mecanismo más arraigado de expresión de la opinión popular. En 1974 sólo 39 países - uno de cada cuatro- eran democracias independientes. Actualmente, 117 países — casi dos de cada tres- escogen a sus dirigentes en elecciones abiertas. Pero la celebración de votaciones periódicas no significa necesariamente que el Estado responda mejor a los intereses de la población. Se precisan otros mecanismos para asegurar que las inquietudes de los grupos minoritarios y pobres se reflejen en las políticas públicas. La representación de genuinas organizaciones intermediarias en los círculos encargados de la formulación de políticas es un primer paso importante para reflejar en ellas los intereses de la ciudadanía. Estas organizaciones, que son incluso más eficaces en los niveles local y provincial de gobierno, están desplegando una intensa actividad en los países en desarrollo, particularmente en aquellos en que la actuación del Estado ha sido deficiente y en que no se ha prohibido el establecimiento de organizaciones de esta índole.

\section{Ampliar la participación}

Cada vez hay más indicios de que los programas estatales son más eficaces cuando se recaba la participación de los presuntos usuarios y cuando se procura aprovechar el acervo social de la comunidad, en vez de luchar contra él. Los beneficios de este enfoque para los organismos gubemamentales se manifiestan en una ejecución más eficiente, una mayor sostenibilidad y un mejor intercambio de información. Los mejores resultados obtenidos con los sistemas de saneamiento de arrastre hidráulico en Recife (Brasil), con los planes de viviendas para la población pobre en Port Elizabeth (Sudáfrica), con los sistemas de ordenación forestal en el estado de Gujarat (India) y con los servicios de salud en Kartum (Sudán) son testimonio de la importancia de la participación de la población local. Por el contrario, las actividades impuestas desde arriba muchas veces fracasan.

La formulación de las políticas en los países prósperos se inscribe en procesos consultivos que brindan a la sociedad civil, a los sindicatos y a las empresas privadas oportunidades de participación y supervisión. En Asia oriental, algunos organismos deliberativos basados en la participación del sector público y privado - por ejemplo, las reuniones mensuales de promoción de exportaciones de Corea, el Comité consultivo nacional conjunto público y privado de Tailandia y el Consejo empresarial de Malasia - constituyen medios útiles para la comunicación de los resultados, el intercambio de información y la coordinación. 


\section{Delegar el poder, con cientas precauciones}

Normalmente, los gobiemos están más centralizados en los países en desarrollo que en los desarnollados. Sin embargo, con algunas excepciones significativas, durante los últimos 30 años en los países en desarrollo las facultades para efectuar gastos públicos se han desplazado ligeramente del nivel nacional a otros niveles de gobiemo. En las naciones industriales se ha observado la tendencia contraria, es decir, hacia la centralización de esas facultades. En esas observaciones no se tiene en cuenta, por supuesto, la descentralización implícita en las recientes reformas de los mercados que han reducido claramente el poder directo y los recursos del gobiemo central en una amplia gama de países.

La descentralización está produciendo muchos beneficios en China, la India, gran parte de América Latina y muchos otros lugares del mundo. Este proceso puede elevar la calidad del sistema de gobierno y hacer posible una mejor representación de los intereses de las empresas y los ciudadanos. Además, la competencia entre provincias, ciudades y localidades puede alentar la adopción de políticas y programas más eficaces. No obstante, hay que conjurar tres posibles peligros:

- Mayor desigualdad. Existe la posibilidad de que se agraven las desigualdades regionales, lo que es motivo de gran preocupación en China, Rusia y Brasil. La movilidad de la mano de obra constituye una solución parcial para este problema, aunque casi nunca es fácil, particularmente en países con diversas etnias en que los inmigrantes no son siempre bien acogidos.

- Inestabilidad macroeconómica. Los gobiernos pueden perder el control de la política macroeconómica cuando la indisciplina fiscal a nivel local y regional obliga al gobierno central a efectuar frecuentes operaciones de rescate, como ha sucedido en el Brasil.

- Sumisión de los gobiernos locales a los grupos de interés. Existe el grave peligro de que los gobiemos locales se vean dominados por intereses especiales, lo que daría lugar a una utilización inadecuada de los recursos y de la facultad coactiva del Estado.

Estos peligros demuestran, una vez más, que el gobierno central desempena siempre un papel vital en el mantenimiento del desarrollo. El problema está en encontrar la apropiada división de funciones entre las instancias centrales y los demás niveles de gobierno.

\section{Orientaciones estratégicas para la reforma}

Para que el Estado responda mejor a los intereses de la población, es preciso desarrollar mecanismos que hagan posible una mayor apertura y transparencia, incrementen los incentivos para la participación en los asuntos públicos y, si procede, reduzcan la distancia entre el gobiemo y los individuos y comunidades cuyas necesidades está llamado a atender. De ello se derivan cuatro imperativos generales que deben tener presentes las autoridades:

- Entablar, cuando sea oportuno, un amplio debate público acerca de la orientación y prioridades básicas de las políticas. Ello supone, como mínimo, una apertura informativa a la opinión pública y el establecimiento de mecanismos de consulta, como consejos deliberativos y comités populares, para recoger los puntos de vista de los grupos afectados y dar a conocer sus preferencias.

- Estimular, cuando sea posible, la participación directa de los usuarios y otros beneficiarios en el diseño, ejecución y seguimiento de las actividades locales relacionadas con los bienes y servicios públicos.

- Cuando se considere aconsejable la descentralización, proceder siempre en forma escalonada y/o sectorial empezando por las esferas que la necesiten con mayor urgencia. Deberán introducirse también mecanismos eficaces de seguimiento y adoptarse sólidas normas intergubernamentales para frenar la arbitrariedad en los niveles central y local.

- A escala local, hacer especial hincapié en los mecanismos $-y$ en los incentivos horizontales en las relaciones del gobiemo con el resto de la comunidad - que contribuyan a fomentar la responsabilidad y la competencia.

Evidentemente, una estrategia de mayor apertura y descentralización tiene sus peligros. Cuanto más numerosas sean las oportunidades de participación, tanto mayores serán las reivindicaciones que se formulen al Estado. Esto puede incrementar el riesgo de una excesiva influencia por parte de intereses especiales más agresivos o de parálisis total. No se puede permitir que el acercamiento del Estado a algunos grupos lo separe todavía más de otros. Asimismo, si no se adoptan normas claras para la imposición de limitaciones a los diversos niveles de gobierno y no se establecen incentivos para el incremento de la responsabilidad a nivel local, la crisis de gobernabilidad que aflige a muchos gobiernos centralizados se transmitirá a los otros niveles. Pero hay ciertas medidas que pueden adoptarse sin peligro para poner en marcha el proceso de reforma; entre ellas cabría mencionar el uso de la información y la búsqueda del consenso para hacer dicho proceso comprensible a los ciudadanos y a las empresas y aumentar sus probabilidades de éxito. 


\section{Más allá de las fronteras} nacionales: cómo facilitar la acción colectiva a escala mundial

La globalización representa una amenaza para los Estados débiles o gobernados caprichosamente. Pero es también una oportunidad para que los Estados eficientes y disciplinados consigan niveles más altos de desarrollo y bienestar económico, y acentúa la necesidad de cooperación internacional eficaz en la búsqueda de una actuación colectiva de alcance mundial.

\section{Apertura a la competencia externa}

Si bien el Estado todavía puede definir las políticas y normas aplicables a quienes están dentro de su jurisdicción, sus decisiones se ven cada vez más influidas por los acontecimientos mundiales y los acuerdos internacionales. Las personas ahora gozan de mayor movilidad, tienen un nivel más alto de instrucción y están mejor informadas sobre lo que ocurre en otros lugares. Además, el hecho de participar en la economía mundial dificulta todavía más la arbitrariedad gubernamental, reduce la capacidad del Estado de gravar el capital y somete las políticas monetarias y fiscales a un examen mucho más riguroso por parte de los mercados financieros.

El proceso de "globalización" no ha concluido: todavía no ha alcanzado a una buena parte de la economía mundial. Alrededor de la mitad de la población del mundo en desarrollo ha quedado al margen del aumento, tantas veces mencionado, del volumen del comercio internacional y de los flujos de capital iniciado a principios de los años ochenta. En parte, es comprensible que los gobiernos vacilen antes de optar por la apertura a la economía mundial. La participación en esa economía sin fronteras, al igual que la descentralización, acarrea riesgos además de oportunidades. Por ejemplo, puede hacer que los países sean más vulnerables a conmociones relacionadas con los precios externos o a importantes desplazamientos desestabilizadores de los flujos de capital. Ello da una importancia decisiva a la actuación estatal, tanto para hacer frente a esas conmociones como para ayudar a los individuos y a las empresas a aprovechar las oportunidades que brinda el mercado mundial. Sin embargo, no deben exagerarse las dificultades relacionadas con la globalización, en particular si se comparan con los riesgos que supone la total exclusión de ese proceso.
La falta de apertura tiene un precio: una diferencia cada vez mayor entre el nivel de vida de los países que han optado por la globalización y los que no lo han hecho. A fin de incrementar su nivel de ingreso, los países que no se han sumado a ese proceso tendrán que aplicar políticas internas acertadas e incrementar la capacidad del Estado. La integración proporciona un sólido apoyo para esas políticas y amplía sus beneficios, pero no puede reemplazarlas. En este sentido, la globalización comienza en el interior de los países. Pero hay instituciones multilaterales, como la Organización Mundial del Comercio, que pueden cumplir la importante misión de incentivar a los países para que den el salto hacia la globalización.

\section{Promover una actuación colectiva mundial}

La integración mundial ha hecho también que se reclame la cooperación de los Estados para luchar contra amenazas internacionales como el recalentamiento del planeta. Las diferencias económicas, culturales y de otra índole que existen entre los países pueden hacer que esa cooperación resulte difícil y, en ocasiones, imposible. No obstante, es indudable que se precisa una colaboración más estrecha al menos en cinco esferas importantes que trascienden las fronteras nacionales:

- Solución de las crisis regionales. La amenaza de un conflicto nuclear entre las superpotencias ha cedido el paso a una proliferación de conflictos de menor envergadura, que acarrean costosos problemas de socorro a refugiados y de rehabilitación. No existe ningún mecanismo internacional sólido para solucionar estos conflictos o impedir que se produzcan. En la formulación de la política económica y social es necesario realizar un análisis más integrado de la forma en que las políticas estatales (y la asistencia internacional) ayudan a abordar los conflictos incipientes.

- Promoción de la estabilidad económica mundial. Existe una creciente preocupación acerca de los posibles efectos desestabilizadores de los cuantiosos y rápidos movimientos de capital de cartera, en particular en los casos en que una crisis sufrida por un país puede extenderse a otros mercados. Se ha sugerido el establecimiento de diversos mecanismos internacionales para evitar estos problemas, y recientemente el Fondo Monetario Internacional ha creado un nuevo servicio para ayudar a sus países miembros a hacer frente a súbitas crisis financieras. Pero la mejor protección para los países será la aplicación de políticas económicas prudentes y flexibles. La creciente movilidad laboral internacional está planteando también numerosos problemas que requieren una actuación colectiva internacional. 
- Protección del medio ambiente. Entre los apremiantes problemas ambientales de alcance mundial están los cambios climáticos, la pérdida de biodiversidad y la protección de las aguas internacionales. La acción colectiva internacional puede ayudar en este sentido haciendo posible una mejor coordinación, una mayor sensibilización de la opinión pública, una transferencia más eficaz de tecnología y prácticas nacionales y locales más eficaces. Pero el progreso es lento, por lo que existe el temor de que tendrá que ocurrir una grave catástrofe ecológica para que los países tomen medidas concertadas en esta esfera.

- Fomento de la investigación básica y generación de conocimientos. El Grupo Consultivo sobre Investigaciones Agrícolas Internacionales (CGIAR), que se está revitalizando para poder dar respuesta a los nuevos desafíos surgidos en relación con la producción de alimentos, ha demostrado que es posible crear y difundir la tecnología mediante una acción colectiva internacional. Es preciso elaborar mecanismos similares de consulta para abordar otros problemas acuciantes de investigación en las áreas de la protección ambiental y la salud.

- Mayor eficacia de la asistencia internacional para el desarrollo. Para que sea más eficaz, la ayuda exterior debe estar más estrechamente vinculada con las políticas de los países receptores. Los organismos de asistencia deben atribuir gran prioridad a la canalización sistemática de recursos a los países pobres que aplican políticas acertadas y han mostrado su firme compromiso con el fortalecimiento institucional.

\section{Eliminación de los obstáculos a la reforma del Estado}

La historia de la reforma del Estado en las actuales naciones industriales es motivo de esperanza -y de reflexión - para los países en desarrollo. Hasta el siglo pasado, los países de Europa y América del Norte y el Japón experimentaban muchos de los problemas que ahora parecen mermar la eficacia del Estado en el mundo en desarrollo. Con el tiempo, superaron esos problemas y se convirtieron en Estados modernos dotados de sistemas profesionales. Ello nos permite concebir esperanzas. Pero también nos obliga a reflexionar, pues el fortalecimiento institucional es un largo proceso. Tuvieron que transcurrir casi 25 años para que arraigaran las reformas de la restauración Meiji, que puso al Japón en la senda del desarrollo. Si bien es posible lograr un Estado más eficaz, el proceso es lento y requiere un compromiso políico inquebrantable. Para ello, hay que actuar sin pérdida de tiempo.

Durante los últimos 15 años muchos gobiernos han respondido a las presiones intemas y externas implantando trascendentales reformas para mejorar su eficacia. Las modificaciones de la política macroeconómica -relacionadas con los tipos de cambio y la política fiscal y comercial- son, en general, las que se han aplicado con mayor rapidez. Estas reformas, aunque tienen repercusiones políticas, no exigen una transformación radical de las instituciones. Un pequeño núcleo de tecnócratas competentes puede aplicarlas en breve plazo, muchas veces por decreto. Lo único que hace falta es la voluntad política de cambiar. Otras reformas, relacionadas con el sistema normativo, los servicios sociales, las finanzas, la infraestructura y las obras públicas, no pueden implantarse tan velozmente porque suponen la modificación de estructuras institucionales establecidas para finalidades diferentes y que responden a reglas del juego distintas. Este tipo de reformas instiucionales entraña cambios dolorosos en la forma de pensar y actuar de los organismos gubemamentales $y$, con frecuencia, exige también un replanteamiento total de sistemas ancestrales de clientelismo político y corrupción. Pero, si realmente se desea mejorar la capacidad del Estado, el cambio es irrenunciable. La combinación de ambos elementos - políticas acertadas e instituciones estatales que puedan aplicarlas con mayor eficacia- permite un desarrollo económico mucho más rápido (Gráfico 5).

La implantación de reformas profundas, como las mencionadas, requerirá mucho tiempo y esfuerzo en gran parte de los paises en desarrollo, y el programa de acción acusará notables diferencias de unas regiones a otras (Recuadro 3). La reforma tropezará también con una fuerte oposición política. Pero se puede dar un importante paso inicial fortaleciendo los organismos centrales y su capacidad de formulación de políticas estratégicas, aumentado la transparencia y la competencia, desglosando actividades y organismos cuyos resultados puedan especificarse fácilmente, contando más con la opinión de los usuarios sobre los servicios recibidos y colaborando con los sindicatos en la formulación de programas que permitan a los trabajadores buscar la seguridad en el cambio más que la seguridad frente al cambio.

\section{¿Cuándo se producen las reformas?}

Las limitaciones y los conflictos de distribución firmemente arraigados en las instituciones estatales son la causa que explica por qué son tantos los países que no llegan a introducir reformas. Pero esas instituciones no son inmutables. En definitiva, el cambio se produce cuando los incentivos para deshacerse de 


\section{Graterecos}

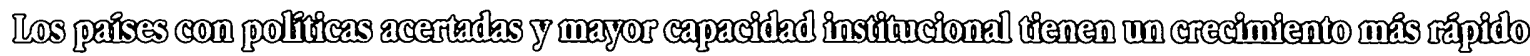

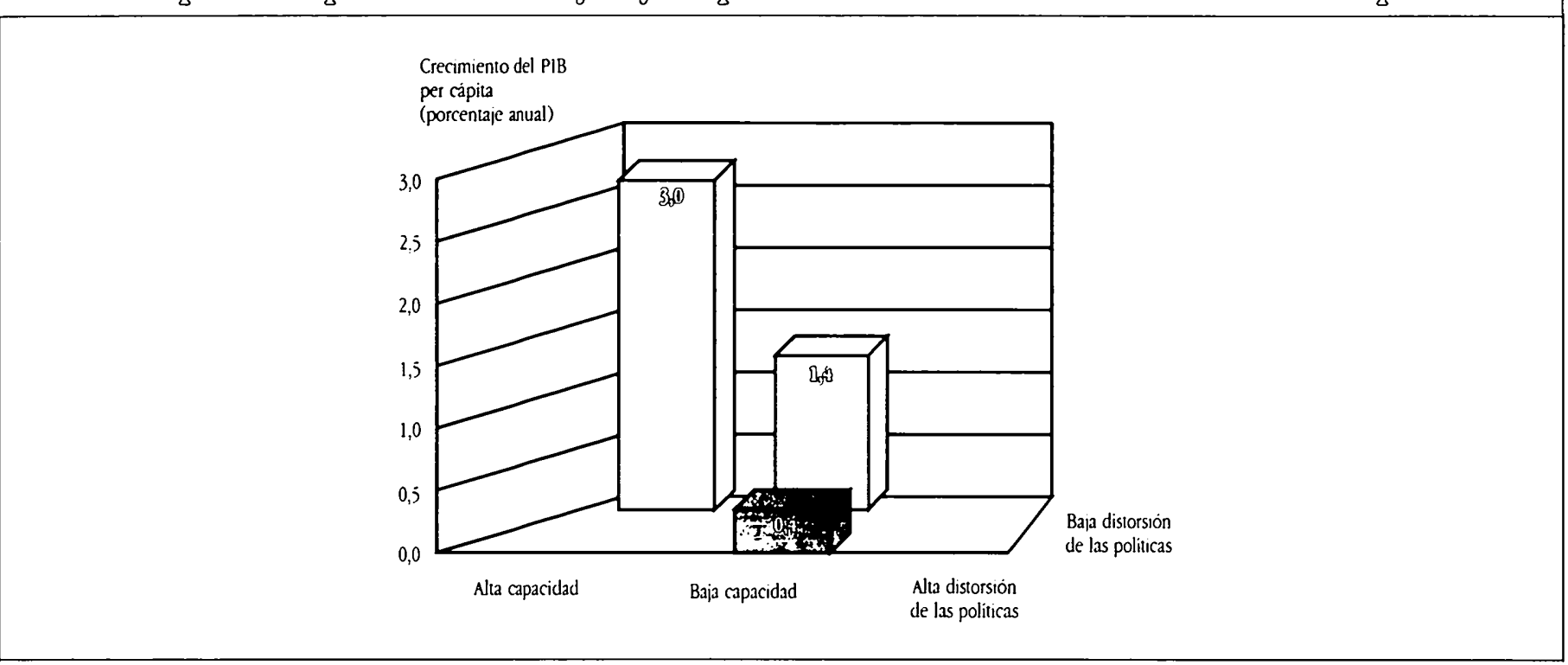

Nota: Cada tasa de crecimiento representa el promedio de un grupo de paises. Los resultados se basan en una regresión, con datos de panel correspondientes a 94 países industriales y en desamollo durante 1964-93, con controles para la educación, el ingreso y otras variables. Véanse más detalles en la Nota técnica.

Fuente: Documento de antecedentes de Cosmander, DAvOODI y lEE.

las políticas y mecanismos institucionales heredados del pasado pesan más que los que aconsejan su mantenimiento. El impulso para la reforma puede proceder de una crisis económica o de una amenaza externa o de la instauración de un nuevo gobierno con menos intereses creados en el sistema antiguo. Pero la reforma puede verse demorada si quienes detentan el poder se aferran a políticas trasnochadas porque asi defienden sus propios intereses (o los de sus aliados). A veces el retraso puede ser dolorosamente largo, como en Haití en la época de los Duvalier, o actualmente en el Zaire.

El ejemplo de los países vecinos puede ser también un poderoso acicate para el cambio. La oleada de reformas que está transformando Asia oriental y América Latina y gran parte de Europa oriental y la antigua Unión Soviética demuestra claramente la existencia de efectos en cadena. La amenaza de quedarse atrás puede incitar a los países a mejorar el funcionamiento de su burocracia. Pero las investigaciones realizadas no han explicado todavía por qué algunos países reaccionan ante las crisis y otros no. Por ejemplo, ¿por qué la tolerancia popular de la inflación es, al parecer, mucho menor en Asia que en ciertas partes de América Latina? ¿Por qué algunos países reaccionan mucho antes que otros ante una situación de deterioro económico? En muchos casos se puede prever cuándo se va a emprender la reforma $\longrightarrow$, al menos, si ésta se va a producir o no- teniendo en cuenta a quiénes va a beneficiar o a perjudicar. El proceso de reforma tiene poco aliciente si los beneficiados no pueden compensar a los perjudicados. Pero aun en los casos en que las posibles ventajas son mayores que los inconvenientes, puede ser difícil proceder a la reforma si los beneficios se distribuyen entre un gran número de personas, mientras que los perjudicados, aunque menos numerosos, constituyen un grupo influyente y capaz de hacerse escuchar. Otro problema es que a menudo los beneficios sólo se hacen realidad en el futuro, mientras que las pérdidas son inmediatas. Sin embargo, hay ocasiones en que la situación se ha deteriorado tanto que son muchos más los beneficiados que los perjudicados. En esos casos la reforma puede producir inmediatamente beneficios económicos y políticos.

\section{¿Cómo conseguir apoyo para las reformas?}

Los dirigentes y minorías selectas interesados en impulsar la reforma pueden acelerar ese proceso adoptando decisiones que amplien las posibilidades de elección de los ciudadanos, hagan percibir más claramente los beneficios y garanticen que las políticas tengan más en cuenta a todos los grupos. En los últimos años, algunos dirigentes políticos clarividentes han transformado las opciones a disposición de su pueblo mediante la adopción de decisivas medidas de reforma. Tuvieron éxito porque hicieron que los beneficios del cambio resultaran evidentes a todos los afectados, y forjaron coaliciones que dieron mayor peso a grupos de beneficiarios que hasta entonces se habían 


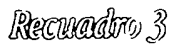

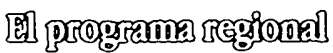

A continuación se resumen los componentes y desafios fundamentales del proceso encaminado a aumertar la ef:cacia del Estado en las diversas regiones en desarrollo. Inevitablemente, se trata de generalizaciones amplias, y cada grupo regional abarca varios países con experiencias muy diferentes.

- En muchos países de África al sur del Sabara el Estado se encuentra en crisis, una crisis de falta de capacidad. Esos países deben atribuir prioridad urgente a la reconstrucción de la eficacia del Estado mediante una reorganización radical de las instituciones públicas, el restablecimiento del imperio de la ley y el empleo de controles fidedignos para frenar los abusos del poder estatal. En los países en que los vínculos entre el Estado y la sociedad civil son frágiles y están insuficientemente desarrollados, para mejorar los servicios públicos y colectivos deberán forjarse relaciones de asociación más estrechas con el sector privado y la sociedad civil.

- En la mayoría de los países de Asia oriental no puede decirse que la capacidad del Estado constituya un problema, pero la medida en que éste pueda transformarse para hacer frente a los nuevos desafíos de la región será fundamental para el continuado éxito de su economía.

- En Asia meridional el problema más importante es una reglamentación excesiva, que es causa y efecto del desmesurado número de empleados públicos y la ruta más segura hacia la corrupción. La simplificación de la reglamentación y la reforma de las empresas públicas, con la consiguiente contracción de la función del Estado, será una tarea compleja y políticamente difícil.

- La reorientación del Estado hacia una nueva función $\longrightarrow$ Señalar el rumbo, no remar - dista de haberse terminado en Europa central y oriental. Pero la mayoría de los países han alcanzado progresos y están logrando mejoras en materia de capacidad y responsabilidad.

- La baja capacidad estatal en muchos países de la Comunidad de Estados Independientes (CEI) es un obstáculo grave y cada vez mayor para su progreso en casi todas las esferas de la política económica y social. En la CEI el proceso de reorientación del Estado se encuentra todavía en una fase inicial, y han surgido graves problemas a causa de la falta general de responsabilidad y transparencia.

- La descentralización del poder y del gasto, acompañada de la democratización, ha provocado una impresionante transformación del panorama político en América Latina, produciendo lo que algunos han denominado una «revolución silenciosa. En la región está surgiendo un nuevo modelo de gobierno. Es necesario, sin embargo, que los países hagan también más hincapié en la reforma del sistema jurídico, la administración pública y las políticas sociales.

- En el Oriente Medio y Norte de África el desempleo es, con mucho, el problema económico y social más importante, por lo que resulta particularmente difícil reducir las dimensiones del sector estatal. Dado que las dificultades políticas y sociales relacionadas con la reforma son notables, aunque no insuperables, una buena solución podría ser comenzar a descentralizar algunos servicios y concentrarse en la reforma de las empresas estatales, al mismo tiempo que se sientan las bases para reformas de mayor envergadura.

mantenido en el anonimato. Su éxito también se debió -y éste es un factor crucial- a que articularon una visión a plazo más largo para la sociedad, lo que permitió a la población ver más allá de los sufrimientos inmediatos del ajuste. Los buenos dirigentes consiguen que la población se sienta identificada con la reforma, que se convenza de que ésta no es algo que viene impuesto desde el exterior.
Para la reforma del Estado se requiere la cooperación de todos los grupos de la sociedad. La indemnización de los grupos perjudicados por la reforma (que no siempre son los más pobres de la sociedad) pueden ayudar a obtener su apoyo. Aunque a corto plazo esa indemnización puede resultar costosa, a la larga es rentable. Las diferencias arraigadas entre los diversos grupos y la desconfianza mutua son también factores que pue- 
den retrasar la reforma. No hay soluciones rápidas para acabar con enemistades ancestrales, pero los pactos sociales, como los Pactos de la Moncloa concertados en España y la Conferencia Económica Nacional celebrada en Benin, pueden tener un efecto positivo.

Los organismos internacionales pueden alentar y ayudar a mantener el proceso de reforma en cuatro formas diferentes. Primero, pueden brindar valioso asesoramiento técnico sobre lo que se debe y lo que no se debe hacer. Este asesoramiento resulta con frecuencia valiosísimo, en particular para los Estados más pequeños que carecen de los recursos necesarios para resolver por sí solos los problemas técnicos. Pero tiene que complementarse con conocimientos especializados autóctonos que permitan adaptar las reformas a las condiciones e instituciones locales. La Organización Mundial del Comercio desempeña un papel muy importante en la reforma comercial, la Organización Mundial de la Salud en las cuestiones sanitarias, y la Organización Internacional del Trabajo en lo relativo a la legislación laboral y política de empleo. Segundo, los organismos internacionales pueden aportar un rico acervo de experiencia internacional acerca de toda una gama de problemas. Estos organismos, cuyo personal en muchos casos es originario de todas las regiones del mundo, pueden aportar expertos de extracción muy diversa. Tercero, la asistencia financiera que facilitan los organismos internacionales puede ayudar a los países a soportar el difícil período inicial del proceso de reforma, hasta que comiencen a producirse los beneficios. Cuarto, estos organismos pueden ofrecer a los países un mecanismo para la concertación de compromisos externos, lo que haría más difícil que dieran marcha atrás en el camino de la reforma. Ahora bien, si alguna enseñanza se desprende de la historia de la asistencia para el desarrollo es que el apoyo externo sirve de poco si no existe una voluntad interna de reforma.

\section{El buen gobierno no es un lujo, sino un artículo de primera necesidad para el desarrollo}

La proximidad del siglo XXI trae consigo grandes promesas de cambio y razones para sentirse esperanzados. En un mundo caracterizado por vertiginosas transformaciones de los mercados, las sociedades civiles y las fuerzas mundiales, el Estado se ve obligado a ser más eficaz, pero no se está adaptando al ritmo que requieren las circunstancias. Como era de prever, no hay un modelo único para el cambio, y con frecuencia las reformas se implan- tan con lentitud porque exigen un replanteamiento fundamental de las funciones de las distintas instituciones y de la interacción entre ciudadanos y gobiernos. Pero las cuestiones que se examinan en este Informe forman ya parte integrante de la nueva concepción del Estado en muchas partes del mundo, y se han incorporado al programa de los organismos internacionales que brindan asistencia a ese proceso.

La población de los Estados ineficientes sufre desde hace tiempo los efectos de esta situación: lento crecimiento y escaso desarrollo social. Pero los Estados que no emprendan ahora el camino de la reforma quizá tengan que pagar un precio todavía mayor: disturbios políticos y sociales y, en algunos casos, desintegración, con graves repercusiones para la estabilidad, la capacidad productiva y la vida humana. El enorme costo del desmoronamiento estatal ha obligado, lógicamente, a hacer especial hincapié en la prevención, que representaría una vía preferible y potencialmente menos costosa, pero en la que no hay atajos posibles. Una vez puesto en marcha el proceso de desintegración, no valen las "soluciones de emergencia".

Los casos de desmoronamiento del Estado son extremos y poco comunes, pero están aumentando. Como se explica en este Informe, no pueden hacerse generalizaciones sencillas acerca de sus causas y efectos, ni existen soluciones fáciles para su reconstrucción; cada caso plantea desafíos singulares para los países afectados, sus vecinos y el sistema intemacional. Pero, casi siempre, quien paga las consecuencias es la gente común. Ello demuestra, una vez más, que la existencia de un Estado eficaz y atento a las necesidades de la población es decisiva para la salud y prosperidad a largo plazo de la sociedad.

Los esfuerzos por incrementar la eficacia del Estado, incluso en las naciones con tradición industrial, permiten pensar que los beneficios de las mejoras progresivas son considerables. Así ocurre particularmente en los países donde esa eficacia es baja. A través del tiempo se ha demostrado que aun la más mínima expansión de la capacidad del Estado tiene efectos enormes en la calidad de vida de la población, entre otras razones porque las reformas tienden a crear su propio círculo virtuoso. Las pequeñas mejoras en la eficacia del Estado dan lugar a niveles de vida más altos, lo que a su vez sienta las bases para nuevas reformas y una mayor expansión del desarrollo.

Un examen de las economías del mundo en 1997 mostraría la existencia de un sinnúmero de ejemplos de círculos virtuosos. Pero también aportaría numerosas pruebas de lo contrario: países y regiones atrapados en el círculo vicioso de pobreza y subdesarrollo creado por la crónica ineficacia del Estado. Esa dinámica puede llevar con demasiada facilidad a la violencia social, la delincuencia, la compción y la inestabilidad, problemas todos que socavan la capacidad del Estado para impulsar el desarrollo, e incluso para seguir funcionando. El desafío crucial que se presenta a los Estados es adoptar las medidas, de 
pequeña y gran envergadura, necesarias para conseguir un sistema mejor de gobiemo que sitúe a las economías en una trayectoria ascendente utilizando la doble estrategia propuesta en este Informe. La reforma de las instituciones estatales es un pro- ceso largo, difícil y políticamente delicado. Ahora tenemos una idea más cabal de la magnitud del desafío que representa la reforma, pero tenemos también conciencia mucho más clara de lo que podría costar dejar las cosas como están. 
